\section{EFFECTS OF MORPHINE ON GENERAL MOVEMENTS OF PRETERM INFANTS}

\author{
H.J. Remmelts ${ }^{1}$, N.K. de Vries ${ }^{2}$, A.F. Bos ${ }^{3}$, \\ R.A. Van Lingen ${ }^{4}$
}

${ }^{1}$ Princess Amalia Department of Paediatrics, Department of Neonatology, Isala Clinics, Zwolle,

${ }^{2}$ Department of Paediatrics, Medical Centre

Leeuwarden, Leeuwarden, ${ }^{3}$ Department of

Paediatrics, Beatrix Children's Hospital, University Medical Center Groningen, Groningen, ${ }^{4}$ Princess

Amalia Dpt of Paediatrics, Dpt of Neonatology,

Isala Clinics, Zwolle, The Netherlands

Background: The influence of morphine on the developing central nervous system (CNS) of preterm infants is not fully known. Concern for neurological side effects has lead to hesitancy in using morphine within NICUs. Analysis of general movements (GMs) is a method to evaluate the influence of medication on cerebral function.

Objective: To investigate the influence of morphine treatment on cerebral function of preterm infants by analyzing the quality of their GMs.

Method: Prospective cohort study on preterm infants receiving continuous morphine $(10 \mu \mathrm{g} /$ $\mathrm{kg} / \mathrm{h}$ ) for at least $24 \mathrm{~h}$. We assessed GM-quality before, during and after morphine treatment. To evaluate subtle differences in movement quality, we also determined a motor optimality score (OS, range 8-18) of the GMs. Finally, we determined the relationship between GMs and various clinical factors that might confound our findings.

Results: Twenty-nine preterm infants (GA 31 [25.635.7] weeks, birthweight 1525 [630-3000] grams, median[range]) were studied. After morphine was started, GM-quality and OS did not change. During morphine treatment OS improved, with median OS increasing from 9 to $10(p<0.05)$. After morphine therapy GM-quality and OS improved further, median OS increasing to 12 ( $p<0.01)$. Duration of morphine treatment did not influence GM-quality or OS. GM-quality correlated positively to postnatal age $(r=0.444, p<0.01)$ and negatively to respiratory support $(r=-0.490, p<0.01)$.

Conclusion: Morphine treatment did not impair quality of movements in preterm infants. This study indicates that morphine treatment has no direct adverse influence on the CNS and can be used safely in preterm infants.

\section{THE RELATION BETWEEN NEUROLOGICAL OUTCOME AT TODDLER AGE AND MOTOR REPERTOIRE DURING INFANCY IN EXTREMELY LOW BIRTH WEIGHT (ELBW) INFANTS}

\author{
N. De Vries ${ }^{1,2}, A \cdot$ Bos $^{2}$ \\ ${ }^{1}$ Pediatrics, Medical Centre Leeuwarden, \\ Leeuwarden, ${ }^{2}$ Neonatology, University Medical \\ Center Groningen, Groningen, The Netherlands
}

Objective: To determine the relation between the quality of General Movements (GMs) of ELBW infants at term equivalent age (TEA), at 3 months after term, and neurological outcome.

Methods: We assessed the quality of the motor repertoire (GMs and motor optimality scores, OS), using Prechtl's method, in 13 ELBW infants (GA 27.3 weeks, 25.1-31.9; BW 840 grams, 560-955) at TEA and again at 3 months after term. Normal GMs at 3 months are also known as fidgety movements (FMs). We analyzed the relation between quality of GMs, including OS, and neurological outcome at $2.5 y$.

Results: At TEA 10/13 infants had abnormal GMs. All infants had abnormal leg lifting movements with extended legs. In 9/13 infants the movements appeared stiff. At 3 months, 3/13 infants had abnormal FMs. Concurrent movements were abnormal in 9/13 infants due to monotony and jerkiness. Abnormal posture was seen in 7/13 infants: mostly flat body and limb position $(n=5)$ and/or the presence of an obligatory ATN posture $(n=3)$. None of the children developed cerebral palsy. Cognitive and motor delay was seen in 1 infant. Neurological outcome was not related to GM-quality or OS.

Conclusion: Abnormal GMs at TEA are common in ELBW infants. GMs appear stiff and extended legs are frequently seen. At 3 months FMs are mostly normal, but monotonous and jerky concurrent movements, as well as abnormal flat postures are frequent. These abnormalities do not implicate an abnormal neurological outcome. 